\title{
O MESMO E O OUTRO COMO ESPAÇOS VIRTUAIS DE LEITURA EM ANÚNCIOS PUBLICITÁRIOS
}

\author{
Maria da Conceição Fonseca Silva \\ Universidade Estadual do Sudoeste da Bahia
}

RESUMO: Trabalho no quadro conceitual e epistemológico da Análise do Discurso Francesa, dando ênfase às noções cruciais, referentes ao funcionamento dos discursos, como sujeito, sentido, interdiscurso. Analiso anúncios publicitários veiculados em revistas femininas, tentando observar se os discursos de gênero defendidos pelos sujeitos institucionais subvertem a ordem estabelecida ou mantêm o instituído.

PALAVRAS-CHAVE: Análise do discurso; subjetividade; anúncios publicitários.

"Pedimos expressamente que não achem natural o que sempre acontece. (...) para que nada disto se mantenha."

(Bertoldt Brecht)

1 Considerações gerais

Esse trabalho tem como principal justificativa o fato de os anúncios publicitários, enquanto prática discursiva, funcionarem como espaços discursivos-textuais heterogêneos.

Tento responder às questões: Como se dá o funcionamento de discursos de gênero veiculados em anúncios publicitários publicados em revistas femininas? Como funcionam, nos anúncios analisados, os pontos de deriva que oferecem lugar à interpretação? Como se dá o jogo interdiscursivo, ou seja, o

A Cor das Letras, n.4, p.91-99, 2000. 
jogo do discurso-outro enquanto espaço virtual de leitura, que Omarca o outro como espaço social e de memória histórica?

Para ensaiar algumas respostas, trabalho no quadro conceitual e epistemológico da Análise do Discurso Francesa (doravante AD), analisando peças publicitárias, por integrarem domínios semióticos interdependentes, como pontos de deriva que atuam na (re)construção ou na manutenção dos discursos de gênero em nossa sociedade.

\section{ANÁlise E DISCUSSÃo}

Pêcheux (1983:53) diz que "todo enunciado, toda seqüência de enunciados é, pois, lingüisticamente descritível como uma série (léxico-sintaticamente determinada) de pontos de deriva possíveis, oferecendo lugar a interpretação". Como o texto publicitário é construído a partir de vários domínios semióticos, estarei considerando, nas análises, não só a materialidade lingüística, que releva do domínio semiótico verbal, mas, também, a materialidade pictural, que releva do domínio semiótico não-verbal, como pontos de deriva possíveis que oferecem lugar à interpretação.

Os três anúncios publicitários escolhidos para análise foram selecionados de uma revista feminina de circulação nacional. Neles, há um jogo de todos os elementos que os compõe e que são interdependentes, pois estão submetidos às mesmas condições históricas e as mesmas restrições temáticas. Se considerássemos somente os elementos lingüísticos, poderíamos nos precaver contra os riscos inerentes a qualquer tentativa de uma prática discursiva intersemiótica, como podemos ler em Maingueneau (1984:90). Mas, correríamos outro risco que é o de ficar aquém de uma prática discursiva que integra, além da materialidade lingüística que se inscreve na história, a materialidade que releva de outros domínios semióticos, a exemplo do pictural, e que também se inscrevem na história.

Os dois primeiros anúncios foram veiculados num exemplar de CLAUDIA, em maio de 1997. O primeiro aparece na página 43, e o segundo, na página 45 . O sujeito institucional responsável por ambos é a empresa de lingerie Hope, cuja assinatura aparece nas peças. 


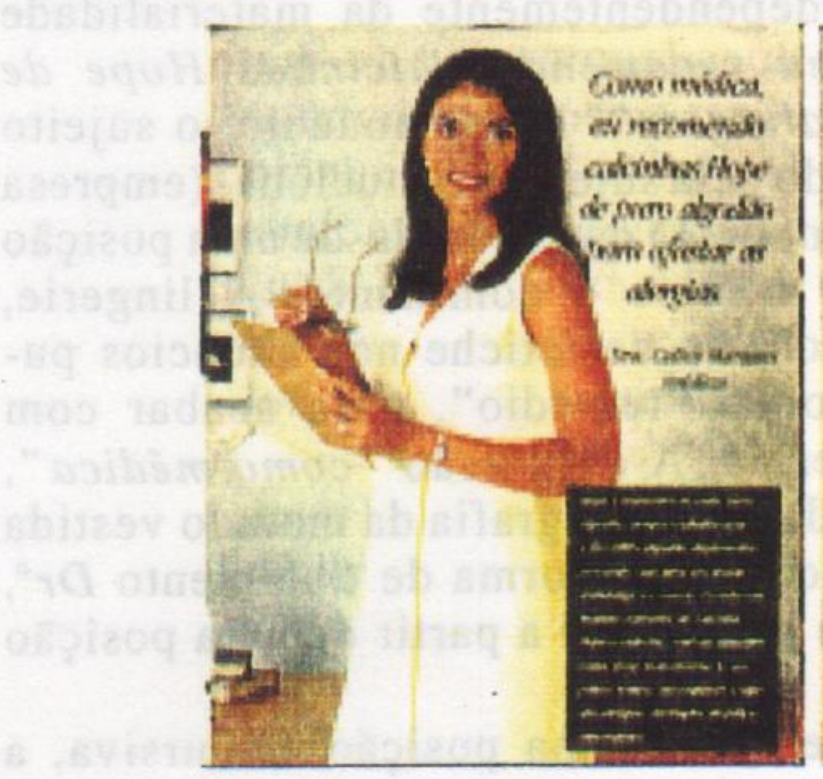

(1)

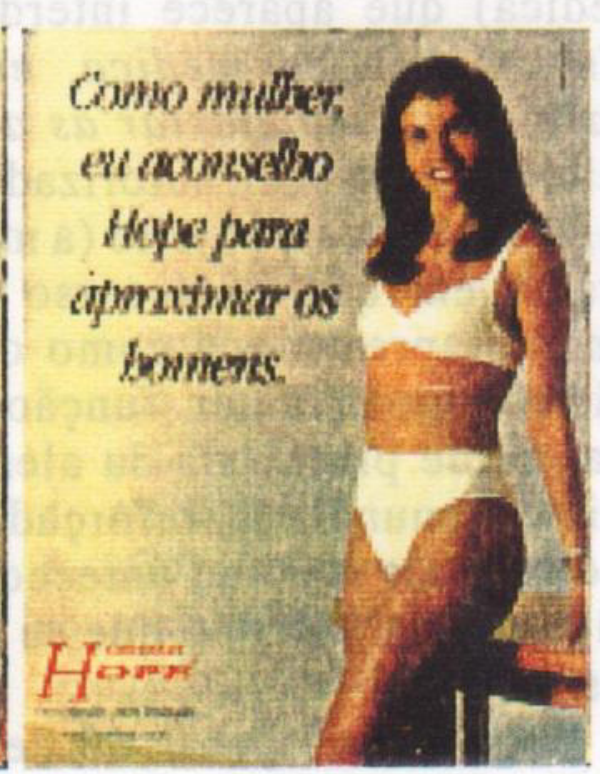

(2)

Podemos observar que tanto (1) quanto (2) integram produções de vários domínios semióticos como pontos de deriva possiveis que ajudam na construção dos significados.

A organização de peça (1) se dá da seguinte maneira: a página é ocupada por uma fotografia de uma modelo de cor branca, cabelos pretos, vestida com roupa branca e que segura óculos de grau, na mão direta, e um envelope, na mão esquerda. Do lado direito da fotografia e atrás da modelo, aparece a seguinte materialidade lingüística: "Como médica, eu recomendo calcinhas Hope de puro algodão para afastar as alergias"; logo abaixo do enunciado, o nome da médica; e, na parte inferior, num quadro de fundo preto, escrito com letras brancas, um texto falando da empresa de lingerie Hope, confirmando a recomendação do enunciado.

A peça (2), por sua vez, apresenta a seguinte distribuição espacial: na parte direita, é apresentada uma fotografia da mesma modelo do anúncio (1). Entretanto, ela (a modelo) aparece vestida de lingerie branca, apoiando-se numa mesa. Do lado esquerdo da página e na frente da modelo, é mostrado a seguinte materialidade lingüística: "Como mulher, eu aconselho Hope para aproximar os homens"; do mesmo lado e na parte inferior, o logotipo da empresa Hope.

São vários os pontos de deriva que levam à interpretação dos dois anúncios publicitários. A peça (1), como podemos ver, apre- 
senta a materialidade pictural (a fotografia de uma modelo vestida de médica) que aparece interdependentemente da materialidade lingüística: "Como médica, eu recomendo calcinhas Hope de puro algodão para afastar as alergias". Nesse anúncio, o sujeito publicitário impessoal, autorizado pela sujeito institucional (empresa Hope), apresenta um sujeito (a modelo) que enuncia de uma posição discursiva em que o discurso médico é dominante. A lingerie, geralmente apresentada como objeto de fetiche nos anúncios publicitários, passa a ter função de "remédio", para acabar com alergia, ou de profilaxia da alergia. A expressão "como médica", que inicia o enunciado, reforçada pela fotografia da modelo vestida de médica mais o nome antecedido pela forma de tratamento $D r^{a}$, delimita, na realidade, o que se pode dizer a partir de uma posição discursiva.

Entretanto, apesar de delimitar uma posição discursiva, a anúncio leva-nos ao primado do interdiscurso. Nessa posição discursiva, o discurso médico, que diz respeito à lingerie e à mulher, constituise e autolegitima-se no jogo do discurso-outro enquanto espaço virtual de leitura, que marca o outro como espaço social e de memória histórica. Outras formações discursivas estão em relação de concorrência com a formação discursiva, cujo discurso médico foi aqui assinalado. Basta montarmos uma rede de paráfrases possíveis para constatarmos os discursos-outros sobre a temática em questão. A expressão "como médica", que marca lingüisticamente uma posição discursiva, pode ser substituída por várias outras, tais como: "como professora", "como mãe", "como mulher", etc, que delimitam outros discursos possíveis. E nesse aspecto, a peça publicitária (1) também vai funcionar como ponto de deriva para a interpretação da peça (2).

Ao tratar do anúncio publicitário (2), não podemos esquecer que ele aparece depois de um intervalo de uma página entre a peça (1). Esse intervalo a qual me refiro não é vazio, pois está implícito um $\boldsymbol{e}$ que tem caráter adversativo ou um mas, que reforça a tomada de posição contrária, demostrada na peça (2) em que aparece a mesma modelo do anúncio (1), mas vestida com lingerie branca e, à sua frente, o enunciado: "Como mulher, eu aconselho Hope para aproximar os homens". Nessa peça, o sujeito publicitário apresenta a mesma modelo enunciando, entretanto, de uma posição discursiva (marcada pela expressão "como mulher"), cujo discurso de 
gênero apresenta a mulher como símbolo de tentação $e$ a lingerie como objeto de fetiche que dá á mulher poderes para seduzir e provocar desejos e comportamentos nos homens. Esse discurso está materializado tanto na fotografia quanto na formulação lingüística que compõem a peça. É o discurso de gênero presente na maioria dos anúncios publicitários relacionados à lingerie.

Nos dois anúncios, podemos ver que a modelo que funciona como locutor é a mesma. Entretanto, enuncia de posições discursivas que determinam o que cada sujeito deve e pode dizer e como cada sujeito pode e deve se comportar. Como médica, a mulher só pode enunciar o que enunciou em (1) e como mulher, o que enunciou em (2).

O sujeito publicitário, na realidade, joga com um sujeito indivíduo que se desdobra em tomadas de posições. E nesse jogo interdiscursivo entre o mesmo e o outro, está, na realidade, legitimando e realimentando os discursos de gênero, que não são efeitos "naturais", mas "convenções", pois são resultados de uma interação social construída, modelada incessantemente em todas as sociedades.

Enfim, a interação entre esses discursos em posição de delimitação recíproca tanto no anúncio (1) quanto no anúncio (2) é uma espécie de tradução ligada a uma interincompreensão, no sentido de Maingueneau (1984, 1987). Uma formação discursiva quando deixa penetrar o seu Outro, na realidade, ela traduz, reinterpreta o enunciado desse Outro. Como o sentido não é "algo estável que poderia ser relacionado a uma posição absoluta, mas se constrói no intervalo entre as posições enunciativas" (1987:120), ocorre interincompreensão entre as formações discursivas que "determina o que se deve falar e o que se deve compreender", mas, ao mesmo tempo, se essa interincompreensão "proíbe que um mesmo sentido circule de um sujeito para outro, ela também possibilita que os sujeitos partilhem o mesmo discurso, "falem a mesma coisa'" (1987:121).

Em se tratando do anúncio publicitário (3), a peça foi veiculada em CLAUDIA, abril 98, entre as páginas que tratam do tema "Atualidades". O sujeito institucional responsável é a empresa Pulligan.

A Cor das Letras, n.4, p.91-99, 2000. 


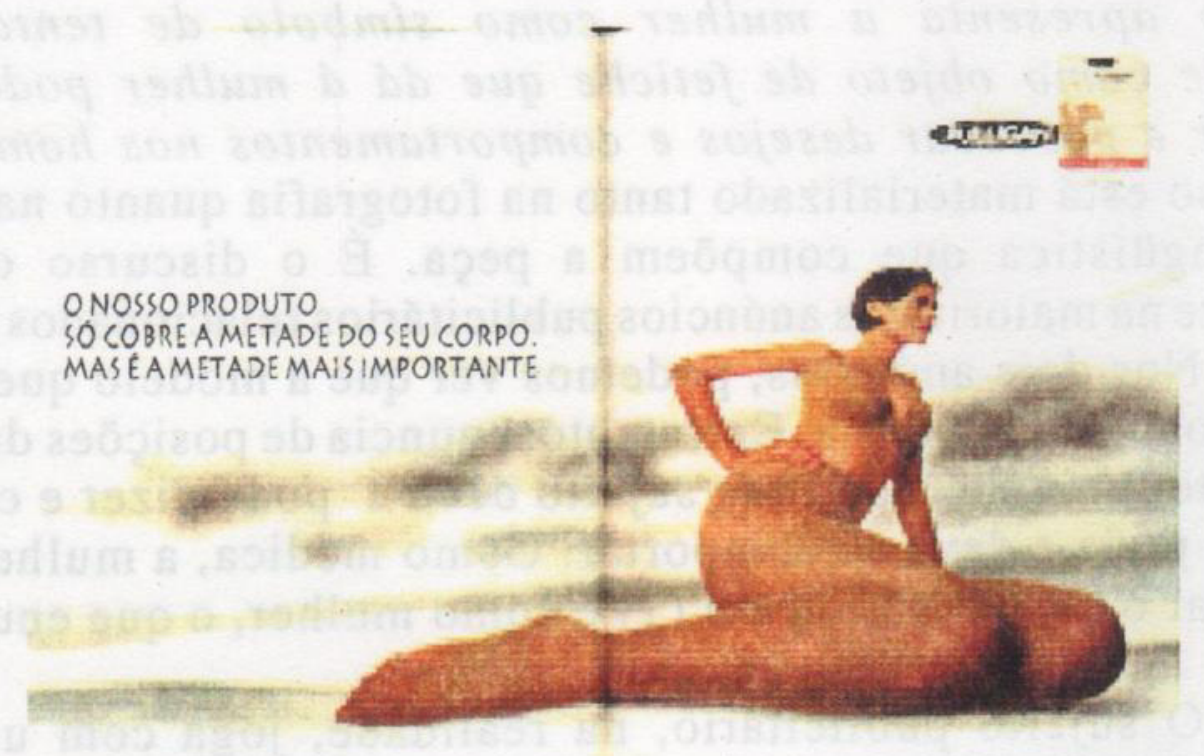

(3)

Este anúncio de meia-calça Pulligan apresenta a seguinte organização: no centro da página 31 , que fica à esquerda do sujeito interlocutor, é mostrada a formulação "O nosso produto só cobre a metade do seu corpo. Mas é a metade mais importante”; da pàrte inferior da página 32 à pagina 33, uma fotografia de uma modelo vestida com sutiã e meia-calça, objeto fetichizado: a parte que está coberta pela meia aparece em destaque, ou seja, a modelo é apresentada em forma de sereia; no canto da página 33, o logotipo.

A materialidade lingüística " $O$ nosso produto só cobre a metade do seu corpo. Mas a metade mais importante" funciona como ponto de deriva para a interpretação da materialidade pictural, ao mesmo tempo em que a materialidade pictural, apresentada no anúncio, funciona como ponto de deriva para a interpretação da materialidade lingüística.

O sujeito publicitário, autorizado pelo sujeito institucional (empresa Pulligan), através dos domínios semióticos mobilizados, coloca em jogo o discursos-outros como espaços virtuais de leitura, que marcam o outro como espaço social e de memória histórica.

O símbolo mobilizado é descrito por Odisseu (apud Schwab, 1974:63) como ninfas que cantam de maneira sedutora, enfeitiçando a quantos lhes escutam as canções. Sentadas às margens verdejantes, elas entoam suas melodias suaves e encantadoras, mas quem se 
deixa seduzir está fadado à morte. Na Idade Média, a sereia era vista como símbolo da sedução mundana e diabólica.

As referências culturais vão sendo produzidas por meio de símbolos, jogos de significação, cruzamento de conceitos e relações de poder. A materialidade lingüística " $O$ nosso produto só cobre a metade do seu corpo. Mas a metade mais importante", que aparece interdependente do símbolo mobilizado, marca uma posição discursiva cujo discurso de gênero assinala uma memórica histórica em que o feminino é inferior ao masculino, frágil, desprovido de razão e, portanto, incapaz. Esse discurso está presentificado tanto na formulação quanto na fotografia da modelo que aparece com a cabeça pequena.

A materialidade pictural e a materialidade lingüística, em jogo na peça, constituem as redes de significantes, que mobilizam o acontecimento discursivo que lhes deu origem e do qual retiram sua legitimidade: o mito judaico-cristão, onde há cisão entre sexo e afeto, razão e emoção; onde a mulher foi proibida de ter conhecimentos das leis, pois o conhecimento é fonte de poder e de participação na vida social, política, econômica, etc. Daí o discurso de gênero imposto pela ideologia hegemônica que envolve uma definição de homem e de mulher na diferença e no contraste, no complementar e no desigual.

Isso é poderoso. O discurso de gênero presentificado tanto na materialidade lingüística quanto na materialidade pictural do anúncio publicitário (3) pertence a mesma formação discursiva também daqueles que escreveram o Martelo das Feiticeiras, Bíblia dos inquisidores, onde podemos encontrar o seguinte recorte ou formulação:

Diz-nos Hecira: 'As mulheres intelectualmente são como crianças', (...) Mas a razão natural está em que a mulher é mais carnal do que o homem, o que evidencia pelas suas muitas abominações carnais. E convém observar que houve uma falha, por ter sido ela criada a partir de uma costela recurva, ou seja, uma costela do peito, cuja curvatura é (...) contrária à retidão do homem. E como virtude dessas falhas a mulher é animal imperfeito, sempre decepciona a mente. (KRAMER e SPREENGER, 1484:116).

A Cor das Letras, n.4, p.91-99, 2000. 
Perigoso, também, porque refuta e nega conhecimento totalizante que integra inteligência e emoção, corpo e alma, elementos que desestabilizam o sistema ainda vigente que repousa no controle do poder, no controle do conhecimento dissociado e abstrato, que tem deformado homens e mulheres. $O$ discurso de gênero presentificado no anúncio (3) é poderoso e perigoso, pois afirma a relação de dominação, marcada histórica, cultural e lingüisticamente como natural e universal.

\section{CONSIDERAÇões FinAis, MAS NÃo ÚltimaS...}

Vimos que os anúncios publicitários em análise são práticas discursivas, elaborados a partir do jogo entre domínios semióticos interdependentes que funcionam como pontos de deriva que levam à interpretação.

A interpretação de uma peça publicitária, por sua vez, supõe o jogo interdiscursivo entre o mesmo e o outro como espaços virtuais de leitura. Neste sentido, as materialidades lingüística e pictural dos anúncios analisados, além de funcionarem como pontos de deriva, marcam o jogo do discurso-outro, reforçando os discursos de gênero que mantém o "esta aí".

Os sujeitos publicitários, autorizados pelo sujeitos institucionais das peças (1) (2) e (3), ao mobilizarem as relações sociais de gênero em redes de significantes e de memória histórica, estão, na realidade, legitimando e realimentando discursividade de gênero estabelecida.

Por fim, os meios de comunicação, principalmente as revistas femininas, ao veicularem peças publicitárias do tipo (1), (2) e (3), não apenas reproduzem ou refletem as concepções de gênero que ainda circulam na sociedade. Produzem e reforçam, criando tensões entre o instituído e o que pensam subverter.

ABSTRACT: I worked with the conceptual and epistemologic frame of the Discourse Analysis of the French School, which emphasizes the crucial notions of the discourse as subject, meaning. I analise same addvertisement shown in magazines for women, triyng to verify if the discourses of gender supported by the institutional subjects do not change the "status quo", or they maintain the established. 
KEY WORDS: Discourse analysis; subjectivity; advertisement.

\section{REFERÊNCIAS BIBLIOGRÁFICAS}

KRAMER, H.; SPENGER, J. Malleus Maleficarum: o martelo das feiticeiras; introdução histórica, Rose Marie Muraro; prefácio, Carlos Byington; tradução, Paulo Fóis. Rio de Janeiro: Record: Rosa dos Tempos, 1997. MAINGUENEAU, D. Gêneses do discurso. Bruxelles: P. Mardaga, 1984. MAINGUENEAU, D. Novas tendências em Análise do Discurso. Campinas: Pontes; Editora da UNICAMP, 1987.

PÊCHEUX, M. Discurso: estrutura ou acontecimento? Campinas: Pontes, 1983.

SCHWAB, G. As mais belas histórias da antigüidade clássica: os mitos da Grécia de Roma. Rio Janeiro: Paz e Terra, 1974. 